\title{
NUMERICAL INVESTIGATION OF THE COLD FORMED STEEL PROFILES BOLTED JOINTS
}

Teofil Florin Galatanu ${ }^{1}$

Dorin Radu ${ }^{2}$

UDK: 519.6:624.014.27

DOI:10.14415/konferencijaGFS2017.025

Summary: Present paper describes the numerical investigation of the cold formed profiles joint assembled in a back-to-back pair. There are presented two types of joints, one for which preloading bolts used and the second type for which there were used the bracket joints with normal bolts, where the profiles are inserted in the welded plates joint. The quasi-static loading was applied in the form of concentrated force at the middle of the joint made in a simple supported beam. The F.E. models include the contact between different components and material nonlinearity. There are monitored the evolution of tension in joint, the maximum displacement of the joint beam and the identification of the potential areas for development of the local buckling. The results are based on the numerical studies achieved in the same time with the experimental tests.

Keywords: Cold-formed steel joint, finite element analysis, nonlinear quasi-static finite element

\section{INTRODUCTION}

Although that steel structure where cold-formed profiles used first started to be constructed in USA in 1850s, their usage as load carrying members had been rather limited until 1930s. These profiles were used widely in structural engineering in early $1950 \mathrm{~s}$ after first American Iron and Steel Institute (AISI) standard published in 1946 [1] and their usage increased even more with the development of roll-forming technology. These members have some advantages over hot rolled profiles such as higher moment of inertia/weight ratio, corrosion resistance, more various section types, and fast and easy production. These good results in a lower cost of load bearing capacity and assembly in structures built with cold-formed profiles. Today, cold-formed profiles are used in residential-buildings as load carrying frames, floors and walls. Besides, these profiles can be used as primary and secondary members in many types of structures such as warehouses, hangars, pitched roof industrial and agricultural buildings up to $25 \mathrm{~m}$.

Existing standards used to design cold-formed profiles are based on elastic theory. Rules for the design of cold-formed load carrying members such as floors, roof systems, and residential frames are included in subsequent regulations of the same standard [2]. In short,

\footnotetext{
${ }^{1}$ Teofil Florin Galatanu, dipl.ing. lect., Transilvania University of Brașov, Faculty of Civil Engineering, Turnului 5, Braşov, Romania, tel: +40 268548 228, e - mail: galatanu.teofil@unitbv.ro

${ }^{2}$ Dorin Radu, dipl.ing. asist., Transilvania University of Braşov, Faculty of Civil Engineering, Turnului 5, Brașov, Romania, tel: +40 268548 228, e - mail: dorin.radu@unitbv.ro
} 
various codes of practice for design of cold-formed steel structures given above are only available for the evaluation of section capacities and member resistances of typical sections against both local and overall buckling. Although increasingly used, a comprehensive standard for structures built with cold-formed profiles has not yet been prepared.

One of those structures, namely, cold-formed steel portal frames are generally built by placing cold-formed "C" or "Sigma" or "KB" profiles back-to-back and connecting them to gusset plates with bolts, constituting rafter-rafter (Apex) and column-rafter (Eave) connections (Fig. 1). However, design of those connections relies on engineering experience and knowledge of companies because of the absence of a design standard. Therefore, for instance, destructive consequences might occur due to assumption of fully rigid connections with higher moment capacities calculated, whereas, in reality, are semirigid. This case is not generally taken into consideration by design engineers.

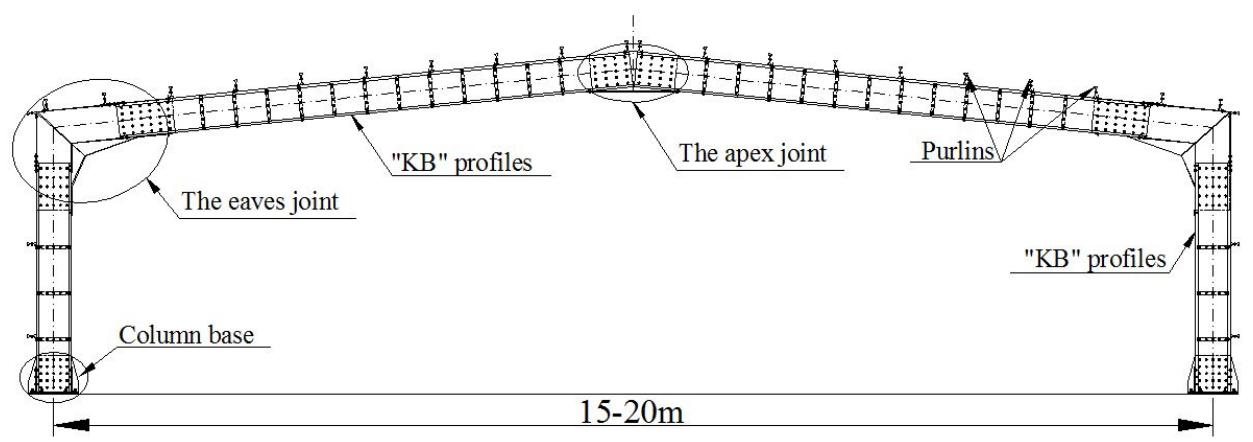

Figure 1. The portal frames built up from cold-formed steel profiles

The thin-walled cold-formed steel profiles used for the joint assemblage are produced by the Kontirom manufacturer and are so-called KB profiles; they have a bracket (cassette) shape and are used as linear elements of the structural resistant frames. A frame element is typically made of two KB profiles positioned back-to-back and fixed together with a thick steel connector, as in the Fig. 2.

The mechanical characteristics of the material are the yield strength of the basic material $\mathrm{f}_{\mathrm{yb}}=\mathrm{f}_{\mathrm{y}}=320 \mathrm{~N} / \mathrm{mm}^{2}$, the ultimate strength of the basic material, $\mathrm{f}_{\mathrm{u}}=390 \mathrm{~N} / \mathrm{mm}^{2}$, so the ratio $\mathrm{f}_{\mathrm{u}} / \mathrm{f}_{\mathrm{y}}=390 / 320=1,22>1,2$.

The thin-walled profiles are manufactured with the thickness from $1,5 \mathrm{~mm}$ to $5,0 \mathrm{~mm}$ and the height of the cross section from $250 \mathrm{~mm}$ to $600 \mathrm{~mm}$ [3].

Their design and engineering is carried out according to Eurocode 3 provisions- EN 1993$1-3$, and for the joints where the thickness sheet profile exceeds $4,0 \mathrm{~mm}$ the recommended standard is Eurocode 3 EN 1993-1-8[4]. Usually the joints are made by means of gussets assembled of welded steel plates [5].

The profiles types "KB" are the ratio between the height of the web and width of the flange relatively large. The flange is finished by stiffeners and some intermediate stiffeners are introduced into the web [3]. 


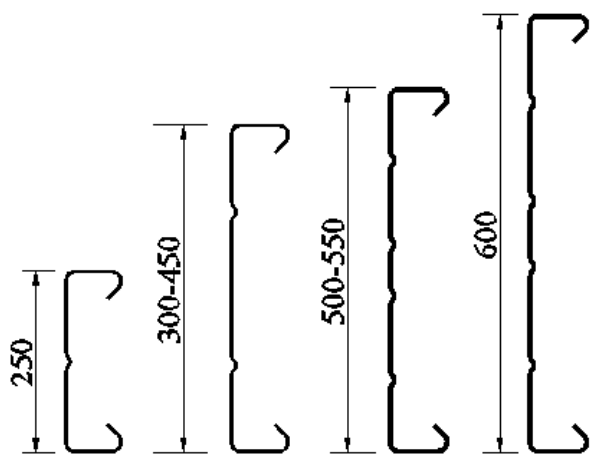

a) $\mathrm{KB}$ sections type

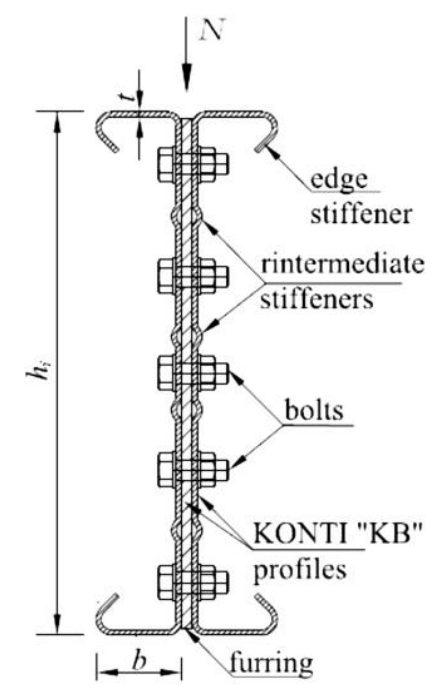

b) Cross section of cold-formed steel portal frame taken at the joints

Figure 2. The thin-walled cold formed steel profiles „,KB”

The reason of the present study is induced by existence of several lacks noticed at the joints connecting the KB elements used for beams and columns of the structures with several destinations.

\section{THE DESCRIPTION OF THE JOINT PROTOTYPE AND OF THE MEANS OF MODELING}

The numerical phase of the study, first finite element models were validated according to experiments performed on specimens with joints which are preloading bolts used and the second type for which there were used the bracket joints with normal bolts.

There are many ways of modeling, but the time and the necessary resources are function of the size of the model to be analyzed. It was proposed to model a girder with a central joint with the static scheme of a simply supported beam, and for the numerical analysis, 
instead of the whole model, there was considered only half of the assembly loaded with the computed value of the reaction. The simply supported beam of length 1 was replaced with a beam of length $1 / 2$ that is simply supported at one end, and at the other (meaning the middle of the real beam) a fixed rotation and a free translation joint. The force applied to the model is half of the force considered for the whole model (it is equal to the support reaction). Material non-linearity in the specimens was modeled by using the Von Mises yield criterion. Residual stress and strain hardening effect in the section resulted from cold forming process were not included in this FE model due to the counteractive effect between them. Element size in joint plate and their interacting parts of KB profiles are between 4 and $8 \mathrm{~mm}$, smaller near bolt holes larger in other parts.

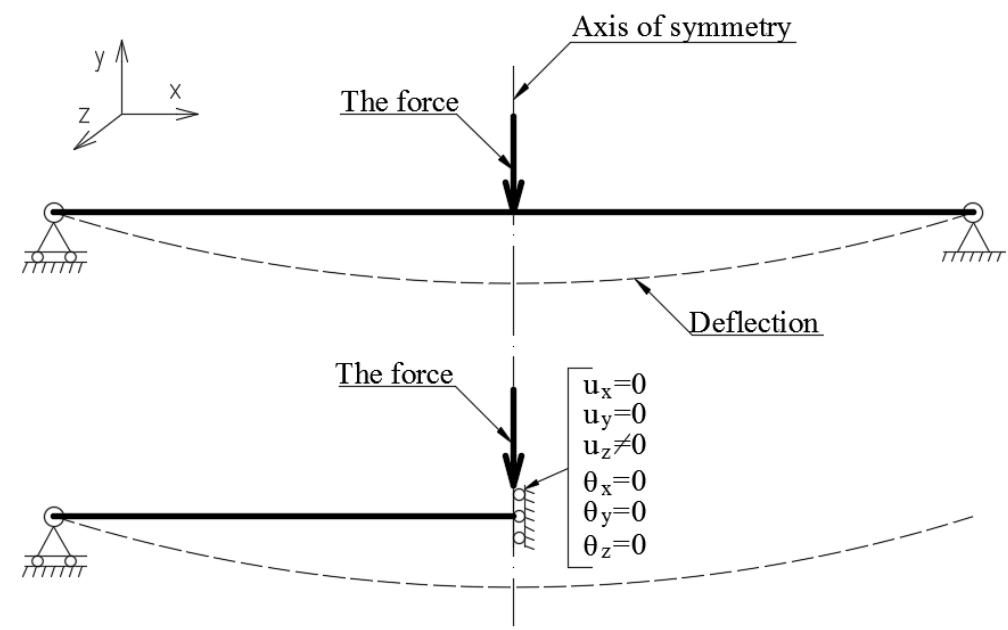

Figure 3. Static scheme of the FE model

The modeling was done using solid finite elements interconnected considering ,contact surfaces-surfaces with friction". In such case, meshing is one of the most important steps, because the accuracy of the results depends on it. The joint is made of distinctive parts: profile, steel plate joint, splice plates between the profiles, bolts, nuts and washers [5].

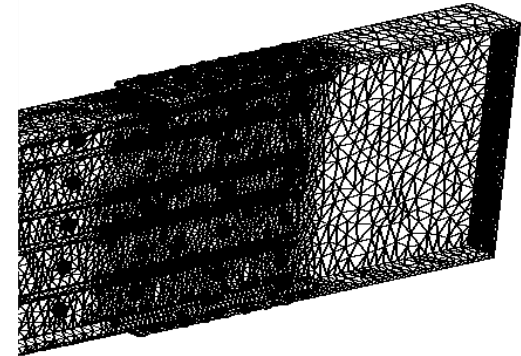

a) girder joint with preloading bolts (G0)

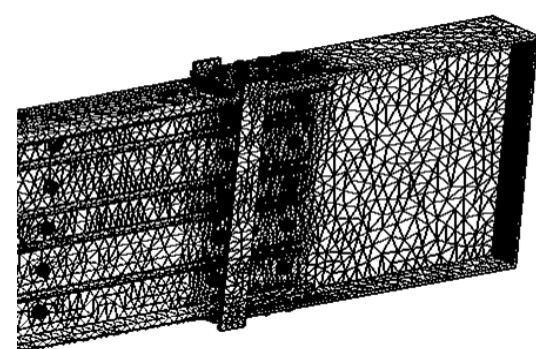

b)the joint of bracket type(GN)

Figure 4. Meshing of the beams and joints 
Contemporary achievements in civil engineering 21. April 2017. Subotica, SERBIA

A finer modeling of the areas where there is friction contact is imperative for the results to converge, while a too fine meshing leads to significant resources consumption and even to the impossibility to solve the system. Another aspect that was taken into account was the modeling of the contact between the joint surfaces keeping the mounting tolerances [6].

\section{FINIT ELEMENT ANALISYS AND RESULTS INTERPRETATION}

In the first stage there was modeled the joint with preloaded bolts and then, the joint where the profile was inserted in the welded connecting gusset elements $\left(S 355-f_{y}=355 \mathrm{~N} / \mathrm{mm}^{2}\right)$, counting on the bearing capacity obtained by turning the profile in the joint.

If we refer to the typical model with preloading bolts, the minimum principal tension $\sigma_{\text {min }}$ occurs because of the diameter pressure of the bolts that are furthest from the gyration center of the joint. This happens after the friction force is exceeded and the displacement between the surface of the profile and that of the joint has been initiated. The minimum value of the resulting tension on the contour of the holes is close to the yielding strength of the profiles' material $\left(f_{y}=390 \mathrm{~N} / \mathrm{mm}^{2}\right)[6]$.

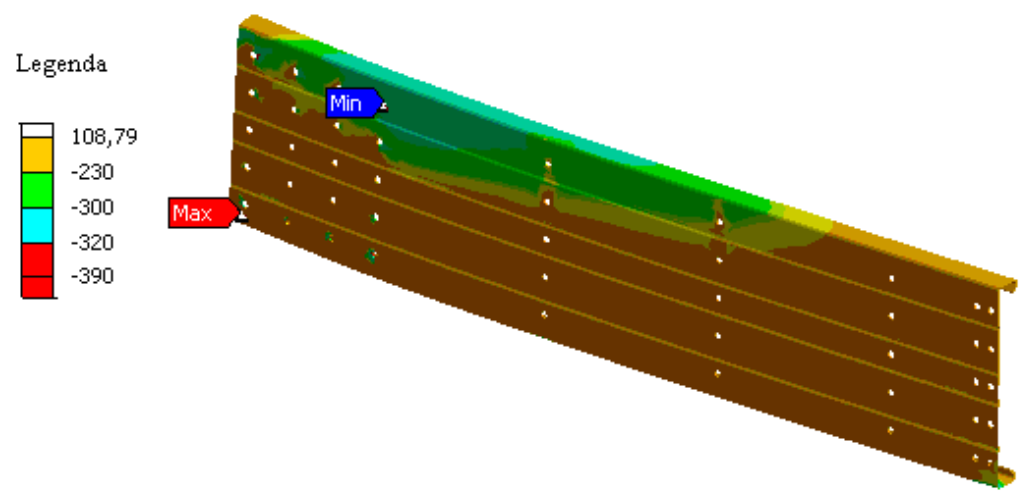

Figure 5. The minimum principal stress $\sigma_{\min }\left[\mathrm{N} / \mathrm{mm}^{2}\right]$

A close look of the displacements shows that the 2KB600-5 beam has a normal behavior with an increase of rigidity in the area of the joint welded connecting gusset elements. The maximum displacement of the joint is approximately $60 \mathrm{~mm}$. But we must take notice that the flanges of the profile tend to curve towards the inside because of the lack of bolts at their level; as a result the local buckling turns up.

Then we passed on to modeling the bracket joints without preloading bolts, where the profiles are inserted in the welded connecting gusset elements.

The difference of displacements of almost $30 \%$ from the beam with preloading bolts and the beam with bracket joint is due, on one hand, to the wedging of the profile in the bracket for the beam that is inserted into the bracket and on the other hand, to the inability to reach a great enough fiction coefficient between the contact surfaces for the preloaded bolted joint. 
Unit: $\mathrm{mm}$

Time: 1

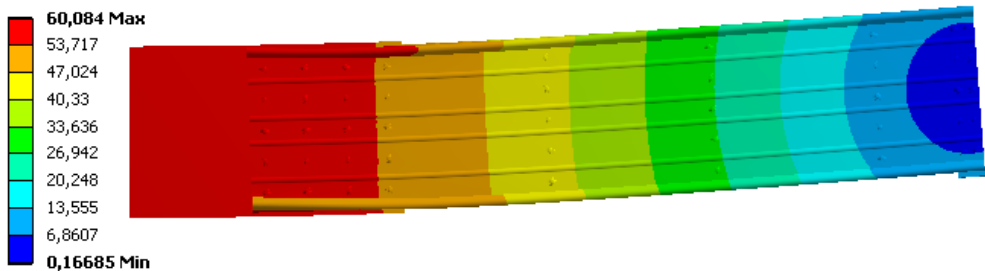

Figure 6. Deformed shape of the beam with preloading bolts on the web [mm]

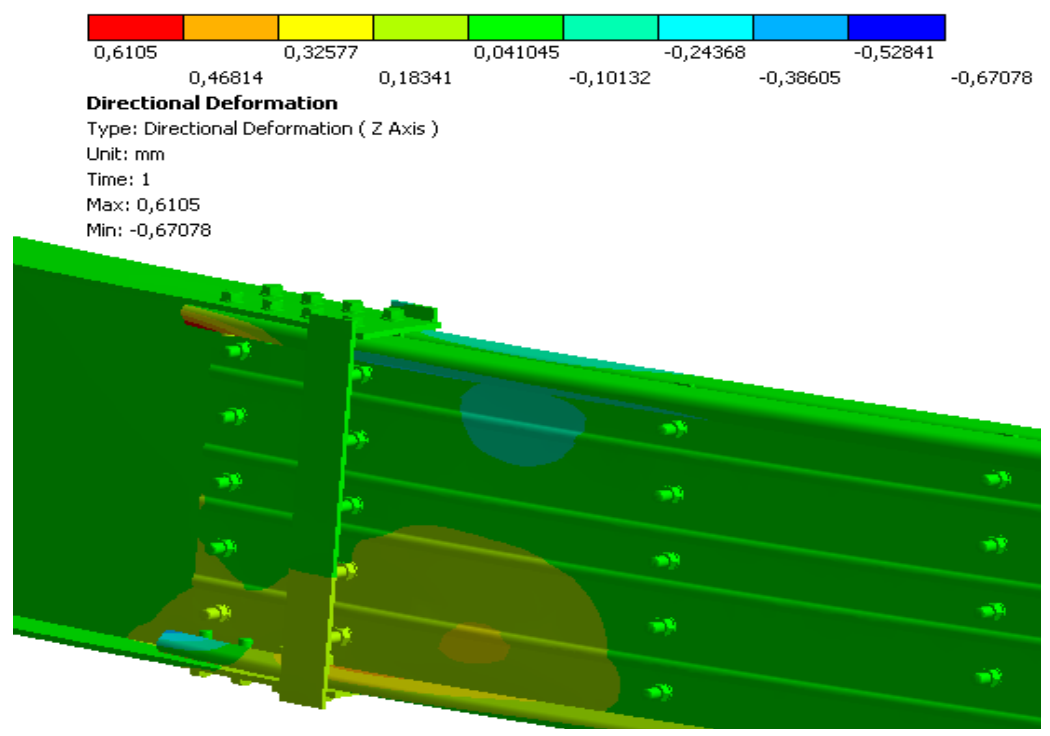

Figure 7. Lateral displacement of the profile in the carcasse [mm] 
Contemporary achievements in civil engineering 21. April 2017. Subotica, SERBIA

The lateral buckling due to the bending-twisting for such a beam that is slender and tall is prevented by points of lateral support. But, as it can be seen in figure 7, buckling waves appear locally near the entering of the profile in the joint, which is difficult to avoid.

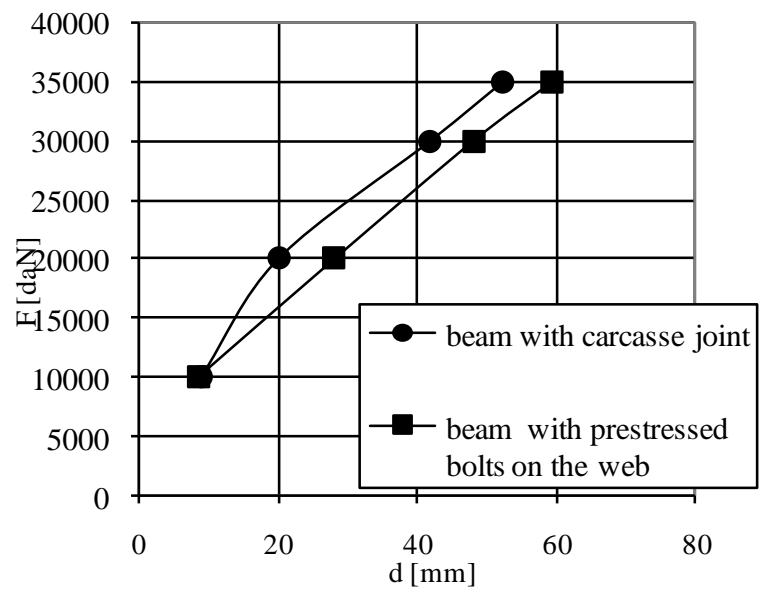

Figure 8. The force-deflection relationship

The joint tensions are uniformly distributed, without exaggerated values in specific areas, except for the tensions due to the pressure on the hole of the bolt.

\section{CONCLUSIONS}

The joints between profiles with thin walls KB type was modeled, fulfilling the real condition by: modeling the contact between the surfaces, keeping the tolerance of assembling between the KB profiles and welded connecting plates elements, modeling the preloading bolts etc. A proper meshing of the beams could be obtained by half reducing the beam of the testing stall. In detail, we could observe the buckling of the web profiles in the end area of the welded steel plate, thing that could not be observed at the load of the beam on the stall. We determined the place of the area with maximum tensions from the node and their way of distribution.

\section{REFERENCES}

[1] AISI. Specification for the design of light gage steel structural members. New York: American Iron and Steel Institute; 1946.

[2] Ozturk, F., Pul, S.: Experimental and numerical study on a full scale apex connection of cold-formed steel portal frames, Thin-Walled Structures, 2015, vol. 94, p.p. 79-88.

[3] Budescu, M., Ciongrandi, I. P., Roşca, O.: Experimental Tests of a New Class of Steel Joints, Intersections, 2005, vol. 2, № 1, p.p. 64-72.

[4] European Standard EN 1993-1-3, Eurocode 3. Design of steel structures - Part 
5.

Савремена достигнућа у грађевинарству 21. април 2017. Суботица, СРБИЈА

1-3: general rules-supplementary rules for cold-formed thin gauge members and sheeting. Brussels: European Committee for Standardization (CEN); 2001.

[5] Galatanu, T.F., Ciongradi, I.P., Budescu, M., Rosca, O.: Experimental studies of the back-to-back connected cold formed steel profile bolted joints, The Bulletin of the Polytechnic Institute of Jassy, 2009, vol. LV, fasc. 1, p.p. 17-28.

[6] Galatanu, T.F., Tuns, I.: Behavior analysis of bolted connections between structural elements made of cold formed steel thin gauge sections, International Conference DEDUCON 70, 2011, p.p 190-196. 